\title{
EL GRAN ESCAPE: SALUD, RIQUEZA Y LOS ORÍGENES DE LA DESIGUALDAD
}

Angus Deaton, The great escape: Health, wealth, and the origins of the inequality, Princeton, Princeton University Press, 2013, 360 pp.

Federico Corredor*

¿Qué molino satánico trituró a los hombres y los transformó en masas? ¿Cuál fue el mecanismo mediante el que se destruyó el viejo tejido social y se intentó sin éxito una nueva integración del hombre y de la naturaleza? Karl Polanyi (1947)

$\mathrm{E}$ n enero pasado Jorge Iván González escribió en La República: "E1 diagnóstico y las conclusiones de Case y Deaton invitan a hacer varias reflexiones. Primero, los logros sociales se pueden perder. Por ello es importante garantizar una institucionalidad que los proteja. Hay ejemplos de involución” (González, 2016). González destaca el rol del ordenamiento institucional y subraya la necesidad de conservar los avances en bienestar que la humanidad ha conseguido hasta ahora.

El último libro del ganador del premio del Banco de Suecia en Economía en 2015, Angus Deaton (2013), es un excelente punto de partida para entender la discusión sobre el bienestar. El gran escape lleva al lector por la senda de las mediciones hasta los orígenes de la divergencia entre las condiciones de vida de los diferentes países. Su mensaje central es que así la humanidad esté mejor que hace 250 años, y muchos habitantes del planeta hayan escapado del hambre, la enfermedad y la pobreza, muchos otros han quedado atrás. Los hechos y datos que presenta sugieren que la humanidad va mejorando pero está en constante amenaza.

La analogía a la que recurre, un desfile olímpico en el que las naciones marchan en orden según las condiciones de vida de sus

* Magíster en Economía, profesor de la Universidad Externado de Colombia, Bogotá, Colombia, [fedecorredor@gmail.com]. Fecha de recepción: 1 de febrero de 2016, fecha de modificación: 26 de febrero de 2016, fecha de aceptación: 12 de mayo de 2016. Sugerencia de citación: Corredor, F. "El gran escape: salud, riqueza y los orígenes de la desigualdad”, Revista de Economía Institucional 18, 34, 2016, pp. 353-360. DOI: http://dx.doi.org/10.18601/01245996.v18n34.21 
pueblos, es muy precisa; los países con mejor desempeño van en los primeros lugares y los países que se encuentran peor, en la cola. El argumento central se refiere a la ausencia de orden y coherencia en ese desfile. Unos salieron más temprano y otros más tarde; algunos no han arrancado, y otros, regados por el camino, van en dirección contraria, es decir, empeoran.

Ese caos refleja la dificultad para medir los logros de bienestar. Por un lado, el concepto de nación es demasiado amplio; no todas las personas que allí habitan mejoran al mismo tiempo, y algunas empeoran, así compartan el mismo territorio. Además, establecer el lapso de tiempo relevante para medir el progreso es todo un desafío. Pero el asunto más difícil es definir el concepto de bienestar. Estos temas han desvelado a varias generaciones de economistas, y constituyen el meollo de este libro, que los trata desde una amplia perspectiva.

\section{LA DESTRUCCIÓN CREATIVA Y LA GRAN TRANSFORMACIÓN}

Algunas de sus ideas centrales hacen recordar inevitablemente a dos grandes economistas del siglo pasado: Joseph Schumpeter y Karl Polanyi. La idea del crecimiento económico como motor de la desigualdad en el mundo y, a su vez, como camino para salir de la pobreza, se puede entender como una reinterpretación del concepto de destrucción creativa de Schumpeter. Al identificar la innovación como causa primera del ciclo económico, este economista austriaco señaló que el proceso mediante el cual unas actividades productivas se volvían obsoletas y otras entraban en escena era inherente a la dinámica del sistema capitalista. Este proceso, en el cual la máquina remplaza la actividad de distintos trabajadores, genera nuevas actividades productivas y empleos, y se puede considerar progresivo. Pero el punto que vale la pena resaltar, en el que Deaton centra su atención, es la necesidad de estudiar con detalle qué pasa con el bienestar de las personas.

En su análisis por países, señala que el origen de la desigualdad es la ventaja temporal de las naciones donde se estableció un aparato institucional suficientemente sólido para el funcionamiento del mercado (p. 294). Indica que la Ilustración fue un gran impulso para crear un ambiente adecuado para la innovación, y llevó a esperar que la mejora del bienestar y de la calidad de vida llegara en forma progresiva a cada nación. La pregunta de fondo se refiere a la situación de quienes no hacen parte del avance de este proceso. Y subraya que el crecimiento, los beneficios de la globalización y el avance tecnológico 
no son universales. Que la pobreza, el hambre y la mala nutrición son realidades de las que muchos no han podido escapar.

Esta atribución de la desigualdad a la dinámica del crecimiento es un punto de conexión con la obra de Polanyi. La desigualdad es una característica esencial del mundo actual, cuyo origen Deaton procura analizar, y su propósito coincide con el de Polanyi: examinar el origen económico y político de nuestro tiempo. La gran transformación (1947) es una obra contundente que pone en cuestión el ajuste espontáneo de las fuerzas del mercado. Y si bien la regulación del mercado no es central en el libro de Deaton, la idea que subyace en la analogía de un gran escape es la posibilidad de que quienes lograron escapar, intenten evitar que los demás los alcancen, estableciendo un sistema político y económico que instaure privilegios, prolongue la desigualdad y socave las instituciones que promueven el crecimiento (p. 217).

E1 propósito de entender los engranajes del progreso humano hace necesario comprender el funcionamiento del sistema político y económico. Una tarea que emprende El gran escape centrando la atención en el bienestar y analizando con rigor sus componentes básicos.

\section{SOBRE LA RIQUEZA DE LAS NACIONES}

Para llegar al núcleo de este libro cabe mencionar un hecho bien conocido: "Todo hombre es rico o pobre según el grado en que pueda gozar de las cosas necesarias, convenientes y gratas de la vida" (Smith, 1776). Con esa idea en mente, Deaton examina las condiciones para gozar efectivamente de estas cosas y las condiciones necesarias para obtenerlas: salud y riqueza. El gran escape trata a fondo estos componentes del bienestar. Por su enfoque interdisciplinario, la abundancia de datos e información y su examen crítico, esta parte es la contribución más significativa del libro.

Sobre la salud da claros mensajes. El primero es que así estemos lejos de tener buenas mediciones, la mera información de estar vivo o muerto ofrece enormes posibilidades de análisis; por ello los indicadores de nacimientos y muertes son esenciales para dirigir las políticas públicas. En particular, la evidencia muestra que el descenso de la mortalidad infantil y el aumento de la expectativa de vida se deben al control de enfermedades y a una mejor nutrición, así como a mejores condiciones de sanidad publica (pp. 91-93). También señala que la salud tiene su propia dinámica, diferente de la de la riqueza, y que si bien hay conexiones entre ambas y sería deseable que fueran de la mano, no hay evidencia de que el crecimiento económico implique 
mejor salud. Los datos muestran incluso que la mortalidad infantil se puede reducir sin crecimiento (p. 118).

Deaton evita las explicaciones unicausales y las ve con mirada crítica. Su examen de la mortalidad y la morbilidad sume al lector en la complejidad del tema, sin enredarlo con los pormenores de las publicaciones científicas. Haciendo gala de maestría narrativa, analiza los retos de la buena medición y muestra que aún estamos lejos del ideal, que los pronósticos carecen de precisión y que algunos fenómenos, como el diferente desempeño de hombres y mujeres o la felicidad, aún carecen de explicación satisfactoria.

Es paradójico que con respecto a la medición no haga mayor referencia a los Informes de Desarrollo Humano, a sus índices ni al trabajo en este campo, pues estos informes buscan medir el desarrollo no solo mediante el ingreso nacional sino también en términos de esperanza de vida y alfabetización. No obstante, Deaton fue uno de los principales consultores del Informe de 2003 y es citado y comentado con frecuencia en otros informes. Puesto que es muy conocido por su riguroso estudio de la pobreza, su percepción sobre el alcance y las limitaciones de tales informes habría enriquecido el libro.

En segundo lugar, el autor destaca la importancia del crecimiento a la vez que resalta sus limitaciones. Diferencia la salud y la riqueza como componentes del bienestar y muestra que la creación de condiciones sanitarias básicas y la vacunación de la población son medidas efectivas para reducir la pobreza y mejorar la expectativa de vida. Un aumento considerable de la inversión en investigación es el mejor camino para mejorar el nivel de vida en el largo plazo. Pero indica que el principal problema de estas propuestas para reducir la pobreza y mejorar la salud es que su ejecución depende de la acción colectiva y del orden institucional. La innovación y el progreso científico son esenciales en el tratamiento de enfermedades, pero su evolución está llena de incertidumbre y no son universales. E1 paso de la teoría de los gérmenes al agua potable y al alcantarillado tomó tiempo, pero la mayoría de la población de muchos países aún carece de estas condiciones básicas (p. 97).

Sin una población educada y sin capacidad de gobierno - una estructura administrativa efectiva, burócratas educados, un sistema estadístico y un marco legal bien definido de obligatorio cumplimiento- es difícil o imposible que los países proporcionen un sistema de salud adecuado (p. 125).

Este tipo de argumento es conocido. La trampa de la pobreza describe una dinámica circular. La educación puede ser clave para salir de la pobreza, pero no hay educación por la debilidad institucional. 
Los políticos capturados por grupos de interés no invierten en educación, lo que genera menor capacidad de elegir y poca participación cívica. Deaton observa que en varios países africanos se introducen instituciones similares y la pobreza se perpetúa. Este hecho lo lleva a examinar el ámbito institucional.

\section{PROCESO POLÍTICO Y BIENESTAR SOCIAL}

Los temas que trata $\mathrm{El}$ gran escape llevan directamente a reflexionar sobre el proceso político y el bienestar social. En 1998, el profesor Homero Cuevas publicó un libro con este nombre, que revisaba la trayectoria y las discusiones más relevantes sobre el tema entre los economistas. Allí planteó que el examen de las decisiones públicas era un análisis de la relación entre mercado, poder político y bienestar.

E1 estudio del bienestar implica entrar en el terreno de la ética y la justicia distributiva (González, 1999). Desde esta perspectiva, la economía del bienestar en el sentido de Pareto es reduccionista, porque la abstracción para entender el mundo a través de la caja de Edgeworth y la conclusión de que la curva de contrato lleva al mejor estado de las cosas carecen de un análisis previo de la distribución de la riqueza. A este respecto, Deaton afirma:

Si un incremento de los ingresos más altos no reduce otros ingresos pero perjudica otros aspectos del bienestar, no se puede invocar el principio de Pareto para justificarlo. ¡El dinero y el bienestar son dos cosas diferentes! (p. 214).

Para Deaton es una falacia que un aumento desbordado de los ingresos más altos de la distribución no vaya en detrimento de los grupos de bajos ingresos, y que el énfasis en el dinero sea inapropiado y unilateral. Si se adopta un concepto más amplio de bienestar, que incluye calidad institucional, participación cívica, educación y salud, es claro que la desigualdad económica genera amenazas para la democracia y perjuicios para la población (p. 214).

Si dinero y bienestar son cosas diferentes, y "la pobreza [es el resultado] de malas instituciones, mal gobierno y políticas tóxicas" ( $\mathrm{p}$. 273), la extracción de rentas en la arena política se convierte en un aspecto central. Si bien en el juego de la democracia los grupos de interés ganan y pierden poder, los más adinerados tienen más capacidad para influir en las políticas del gobierno. Y el agente regulador infringe los principios democráticos al trabajar en beneficio de grupos de interés. El gran escape muestra que los conflictos distributivos son más intensos cuando el ritmo de crecimiento se reduce (p. 327). Y la pregunta de cómo crecer subyace en la reflexión. 


\section{CONVERGENCIA TRUNCADA. ¿DÓNDE QUEDAAMÉRICA LATINA?}

Deaton centra su análisis en China e India y muestra que el desempeño mundial promedio ha mejorado porque estos dos colosos han avanzado notablemente en sanidad pública, nutrición y reducción de la pobreza. No obstante, si bien en su libro Deaton procura dar una visión global de la desigualdad, hay un vacío considerable acerca de América Latina y, en general, de los países de medio desempeño.

El tema central es el escape de las naciones desarrolladas y el estancamiento y atraso de las que muestran peor desempeño. El autor recalca la necesidad de establecer un sólido aparato institucional y de mejorar la capacidad del Estado para fomentar el crecimiento y distribuir sus beneficios entre toda la población. Aparte de las naciones que carecen totalmente de esa capacidad, el mensaje para las demás no es muy claro, si bien -como él mismo reconoce- los temas de salud, riqueza e inequidad son universales. De modo que el alcance explicativo y las propuestas que hace son limitados, pues en estos países ha habido un gran escape, con triunfadores y personas que se han quedado atrás, que al sufrir el yugo de la pobreza siguen atadas a los grilletes del hambre y la enfermedad.

Las reflexiones del autor inducen a pensar que los países de desempeño medio lo están haciendo bien y que en el largo plazo alcanzarán a los más desarrollados. Aquí cabe mencionar un arduo debate sobre el crecimiento. Se podría colegir que Deaton confía en la convergencia que predicen algunos modelos, pero no discute el tema, y la imposibilidad de saber si está hablando de convergencia absoluta o condicional impide determinar el desempeño de muchos países, entre ellos, los de América Latina.

Este vacío podría implicar que poco se puede decir sobre la aceleración del proceso de convergencia. Mucho se puede decir de los que están a la cabeza y en la cola, pero no se puede determinar con claridad qué deben hacer los países que, así hayan despegado, no vuelan alto y en forma sostenida.

Quizá quepa recordar el libro de José Antonio Ocampo y Luis Bértola sobre el desarrollo de América Latina. Después de revisar doscientos años de su historia económica, llegan a conclusiones no muy distintas de las de Deaton. Lo que llaman convergencia truncada designa un proceso desigual y discontinuo de crecimiento y desarrollo, que si bien ha avanzado, ha tenido reveses; en el que la configuración interrumpida de instituciones políticas y económicas ha sido determinante (Ocampo y Bértola, 2013). Lo cual nos lleva a discutir qué hacer. 


\section{ECONOMÍA PARA UN PLANETA ABARROTADO}

Ante la amenaza de que los que logaron escapar busquen impedir que los demás los alcancen, Deaton se muestra optimista y considera que "el deseo de escapar está profundamente arraigado [...] La gente puede bloquear los túneles que dejó atrás, pero no puede bloquear el conocimiento de cómo se cavaron esos túneles" (p.327).

E1 debate sobre las medidas que se han de tomar y las recomendaciones de política es interminable. Jeffrey Sachs, conocido por asesorar a la Unión Soviética en su transición a la economía de mercado y por su afán para establecer un sistema económico y político sostenible, es un abanderado de la ayuda internacional para resolver los problemas que enfrenta el planeta. Deaton, en cambio, es un crítico contundente de ella por su gran impacto perjudicial. Desde los años sesenta se han entregado más de 5 billones de dólares a países en desarrollo (p. 275) y muchos de los que han sido objeto de esta ayuda hoy están igual o peor que antes. Aunque la caridad ha sido vendida y comprada a lo largo y ancho del planeta, la evaluación de Deaton rompe mitos y creencias difundidos en todo el mundo sobre su contribución.

Dada la orientación de los objetivos del milenio a eliminar la pobreza, como establece el Informe de Desarrollo Humano de 2003, la crítica de Deaton a Sachs es relevante. Con independencia de quién tiene la razón, es claro que no hay fórmulas mágicas ni gurús del crecimiento. Aunque se pueden presentar estadísticas que favorecen y apoyan cualquier medida o ideología, el punto es que el crecimiento de la economía y el desarrollo de cada país tienen particularidades; de modo que así los académicos más reputados puedan contribuir al avance de los países, sus posiciones y normas de éxito no son determinantes para mejorar el desempeño de los países.

\section{COMENTARIOS FINALES}

El gran escape es un libro esclarecedor. El profesor Deaton escruta y examina el desempeño mundial y los resultados de la tabla de clasificaciones en forma crítica y ponderada. Los aspectos centrales -salud, pobreza y desigualdad- determinan con precisión la situación del mundo y permiten entender su desarrollo. A pesar de las omisiones mencionadas, este es un libro instigador que sugiere conexiones con diversos autores y teorías, algunos de los cuales se mencionan en esta reseña. Cabe hacer una conexión final.

En 1998 la Contraloría General de la Republica publicó una investigación dirigida por Luis Jorge Garay (2002) sobre las características 
de la sociedad y del Estado en Colombia. Sus conclusiones coinciden con las de Deaton. Las condiciones políticas, económicas e institucionales configuran una realidad en la que conviven la desigualdad y las oportunidades. Se podría decir que el mundo, igual que nuestro país, se debate entre la exclusión y el desarrollo.

\section{REFERENCIAS BIBLIOGRÁFICAS}

1. Case, A. y A. Deaton. "Rising morbidity and mortality in midlife among white non-Hispanic Americans in the 21st Century", Pnas 112, 49, 2015, pp. 15078-15083.

2. Cuevas, H. Proceso politico y bienestar social, Bogotá, Universidad Externado de Colombia, 1998.

3. Garay, L. Colombia entre la exclusión y el desarrollo, Bogotá, Contraloría General de la República, 2002.

4. González, J. I. "Políticos, predicadores y mercado. Un comentario a Proceso politico y bienestar social de Homero Cuevas", Revista de Economia Institucional 1, 1, 1999, pp. 137-142.

5. González, J. I. "Las muertes tempranas en Estados Unidos", La República, 22 de enero de 2016.

6. Ocampo, J. y Bértola, L. El desarrollo económico de América Latina desde la independencia, México DF, Fondo de Cultura Económica, 2013.

7. Polanyi, K. La gran transformación. Los orígenes políticos y económicos de nuestro tiempo [1947], México DF, Fondo de Cultura Económica, 2003.

8. Schumpeter, J. Capitalismo, socialismo y democracia [1942], Barcelona, Orbis, 1983.

9. Smith, A. Investigación sobre la naturaleza y causas de la riqueza de las naciones [1776], México DF, Fondo de Cultura Económica, 2006. 